\title{
Article \\ Spectra of Ga-Like to Cu-Like Praseodymium and Neodymium Ions Observed in the Large Helical Device
}

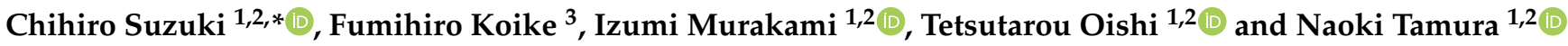 \\ 1 National Institute for Fusion Science, National Institutes of Natural Sciences, 322-6 Oroshi-cho, \\ Toki 509-5292, Japan; mizumi@nifs.ac.jp (I.M.); oishi.tetsutaro@nifs.ac.jp (T.O.); tamura.naoki@nifs.ac.jp (N.T.) \\ 2 Department of Fusion Science, The Graduate University for Advanced Studies, SOKENDAI, \\ 322-6 Oroshi-cho, Toki 509-5292, Japan \\ 3 Faculty of Science and Technology, Sophia University, 7-1 Kioi-cho, Chiyoda-ku, Tokyo 102-8554, Japan; \\ koikef@sophia.ac.jp \\ * Correspondence: csuzuki@nifs.ac.jp
}

check for updates

Citation: Suzuki, C.; Koike, F.;

Murakami, I.; Oishi, T.; Tamura, N. Spectra of Ga-Like to Cu-Like Praseodymium and Neodymium Ions Observed in the Large Helical Device. Atoms 2021, 9, 46. https://doi.org/ $10.3390 /$ atoms 9030046

Academic Editor: Michael Brunger

Received: 25 June 2021

Accepted: 8 July 2021

Published: 14 July 2021

Publisher's Note: MDPI stays neutral with regard to jurisdictional claims in published maps and institutional affiliations.

Copyright: (c) 2021 by the authors. Licensee MDPI, Basel, Switzerland. This article is an open access article distributed under the terms and conditions of the Creative Commons Attribution (CC BY) license (https:// creativecommons.org/licenses/by/ $4.0 /)$.
Abstract: Extreme ultraviolet (EUV) spectra of highly charged praseodymium (Pr) and neodymium $(\mathrm{Nd})$ ions have been investigated in optically thin high-temperature plasmas produced in the Large Helical Device (LHD), a magnetically confined torus device for fusion research. Discrete spectral lines emitted mainly from highly charged ions having $4 \mathrm{~s}$ or $4 \mathrm{p}$ outermost electrons were observed in plasmas with electron temperatures of $0.8-1.8 \mathrm{keV}$. Most of the isolated lines of Ga-like to Cu-like $\mathrm{Nd}$ ions were identified by a comparison with the recent data recorded in an electron beam ion trap (EBIT). The isolated lines of Pr ions corresponding to the identified lines of Nd ions were easily assigned from a similarity of the spectral feature for these two elements. As a result, some of the lines of Pr ions have been newly identified experimentally for the first time in this study.

Keywords: praseodymium; neodymium; highly charged ions; LHD; EUV spectra

\section{Introduction}

It is well known that extreme ultraviolet (EUV) spectra of highly charged ions of lanthanide elements $(Z=57-71)$ are typically composed of quasi-continuum band emissions and/or isolated line emissions due to $n=4-4$ transitions [1-3]. The complex quasicontinuum feature originates from a huge number of unresolved lines emitted from ions with unfilled outermost $4 \mathrm{~d}$ or $4 \mathrm{f}$ electrons, while the isolated lines are mainly emitted from ions having simple electron configurations with one or two outermost $4 \mathrm{~s}$ or $4 \mathrm{p}$ electrons, i.e., $\mathrm{Cu}-, \mathrm{Zn}-, \mathrm{Ga}-$ and Ge-like ions [4,5]. Since the analysis of the isolated lines is easier than that of the quasi-continuum feature, the line identifications of these highly charged lanthanide ions have been attempted so far by using magnetically confined fusion plasmas, laser-produced plasmas and electron beam ion traps (EBITs). For example, systematic studies on lanthanide elements having even atomic numbers from 60 to 70 have been performed at the EBIT facility of the National Institute of Standards and Technology (NIST), which resulted in the identification of a number of unknown lines [6-10]. Nevertheless, experimental data of spectral lines of highly charged ions are still insufficient for some of the lanthanide elements.

In this study, we focus on the EUV spectra of highly charged praseodymium (Pr) and neodymium (Nd) ions observed in the Large Helical Device (LHD), a magnetically confined torus device of the National Institute for Fusion Science (NIFS). There are only a few experimental data available for $\mathrm{Cu}-, \mathrm{Zn}$ - and Ga-like $\operatorname{Pr}(Z=59)$ ions. At first, a $4 \mathrm{~s}^{2}-$ $4 \mathrm{~s} 4 \mathrm{p}$ resonance line of $\mathrm{Zn}$-like $\operatorname{Pr}^{29+}$ ions was identified in a laser-produced plasma [11]. Subsequently, EUV spectra of Pr ions were observed in Texas Experimental Tokamak (TEXT) [12-14], where several prominent lines of $\mathrm{Cu}_{-}, \mathrm{Zn-}$, and Ga-like Pr ions were assigned. However, no EBIT measurements have been reported so far for Pr ions. As 
for $\mathrm{Nd}(Z=60)$ ions, only a few line identifications for highly charged ions had been reported using laser-produced plasmas or magnetically confined fusion plasmas [11,15-19]. Recently, 59 lines of Br-like to Ni-like $\mathrm{Nd}$ ions have been identified in the EBIT facility at NIST [10].

We have already carried out systematic observations of EUV spectra of lanthanide ions in the LHD in the last ten years [19-22]. Though the assignments of some of the isolated lines have been reported, most of the observed spectra are still being analyzed. In this article, we describe the spectral analyses of the isolated lines emitted from Ga-like to $\mathrm{Cu}$-like Pr and Nd ions in high-temperature LHD plasmas. Most of the isolated lines of $\mathrm{Nd}$ ions are assigned by a comparison with the recent EBIT data [10], while the spectra of Pr ions are analyzed based on a similarity to the Nd spectra, which results in new experimental assignments of some of the unreported lines.

\section{Experimental}

The experiments were performed in the LHD, a large-scale magnetically confined torus device for fusion research, as described in our previous papers [19-22]. Accordingly, only a brief explanation is given here. In LHD, a large volume $\left(\simeq 30 \mathrm{~m}^{3}\right)$ doughnut-shape plasma with a major radius of about $3.6 \mathrm{~m}$ is produced under a magnetic field of about $2.75 \mathrm{~T}$ generated by superconducting coils $[23,24]$. Hydrogen plasmas are typically heated up to several keV by neutral beam injection (NBI). The typical electron density is in the order of $10^{19} \mathrm{~m}^{-3}$. Even if heavy ions are injected into a plasma, an electron temperature of 2-3 keV can be maintained by maximum heating and then the electron temperature can be controlled to some extent by changing the heating power. Pr and $\mathrm{Nd}$ atoms are introduced into the plasmas by using tracer-encapsulated solid pellet (TESPEL) [25,26]. We used hydride powder and pure metal fragments for $\mathrm{Nd}$ and $\mathrm{Pr}$, respectively, to inject small amounts (in the order of $10^{17}$ atoms) of solids. The injected impurity ion density is roughly in the order of $10^{16} \mathrm{~m}^{-3}$, which means that optical depth is extremely low and unaffected by transition strength for all the transitions of impurity ions in LHD plasmas.

EUV spectra were measured mainly by a $2 \mathrm{~m}$ Schwob-Fraenkel grazing incidence spectrometer called "SOXMOS" [27] equipped with a $600 \mathrm{~mm}^{-1}$ grating and a micro-channel plate (MCP) detector coated with a phosphor screen. The wavelength coverage of the SOXMOS with this grating is roughly 1-34 nm, in which we can measure simultaneously two different spectral bands of approximately $2-7 \mathrm{~nm}$ bandwidths. A visible image of the phosphor screen was recorded by a linear photodiode array having 2048 pixels. The exposure time of the photodiode array is 0.1 or $0.2 \mathrm{~s}$, and the time evolutions of the spectra were observed sequentially during an entire discharge lasting several seconds. The wavelength resolution of the SOXMOS spectrometer is approximately $0.01 \mathrm{~nm}$. In addition, we employed spectral data recorded in another EUV spectrometer called "EUV_long" [28] with a lower wavelength resolution $(\simeq 0.03 \mathrm{~nm})$ and wider wavelength coverage $(\simeq 4-64 \mathrm{~nm})$. The EUV_long spectrometer is equipped with a flat-field $1200 \mathrm{~mm}^{-1}$ grating and a backilluminated CCD camera. Though the exposure time of the CCD camera was set to $5 \mathrm{~ms}$, 10 consecutive frames (during $0.05 \mathrm{~s}$ ) were accumulated in our analyses to generate spectra with better signal-to-nose ratios. The absolute wavelength scale was calibrated by a third order polynomial fitting of the well known reference lines of intrinsic and injected impurity ions for both spectrometers. The uncertainties of the calibrated wavelengths are less than 0.005 and $0.01 \mathrm{~nm}$ for SOXMOS and EUV_long, respectively.

\section{Results and Discussion}

The injection of Pr and Nd TESPELs has been performed in more than 20 discharges for each element in the last ten years of the LHD experiment. In this study, EUV spectra measured by the SOXMOS and EUV_long spectrometers were analyzed for several selected discharges in which clear discrete spectral lines appeared under stable plasma conditions. The typical discrete EUV spectra of Pr and $\mathrm{Nd}$ ions observed by SOXMOS in the two different spectral ranges, $6.0-10.0 \mathrm{~nm}$ and $9.7-13.6 \mathrm{~nm}$, are shown in Figures 1 and 2, 
respectively. Though the electron temperature is not necessarily kept constant during one exposure time of the detector, the representative central electron temperatures at the middle of the corresponding period are indicated in Figures 1 and 2. As reported in our previous papers [19-22], the spectral feature of highly charged lanthanide ions changes from a quasi-continuum to discrete as the electron temperature rises. As the spectra in Figures 1 and 2 were observed in relatively high temperature conditions, above $0.8 \mathrm{keV}$, the quasi-continuum spectra emitted from lower ion stages were very well suppressed, and the spectra are composed only of discrete features due to higher ion stages such as $\mathrm{Cu}$-, $\mathrm{Zn}$-, and Ga-like ions. Note that the spectral intensity is normalized by each maximum for each wavelength range, and that the Pr spectra are shifted upwards to make them visible in these figures. The dotted lines in the figures indicate background spectra taken before the TESPEL injection, including emissions from intrinsic impurity ions such as carbon and iron. For example, a line at $6.747 \mathrm{~nm}$ in Figure 1 is the second order spectrum of $\mathrm{H}$-like $\mathrm{C}^{5+}$ ions, and a resonance line of Be-like $\mathrm{Fe}^{22+}$ ions at $13.291 \mathrm{~nm}$ is clearly observed in Figure 2.

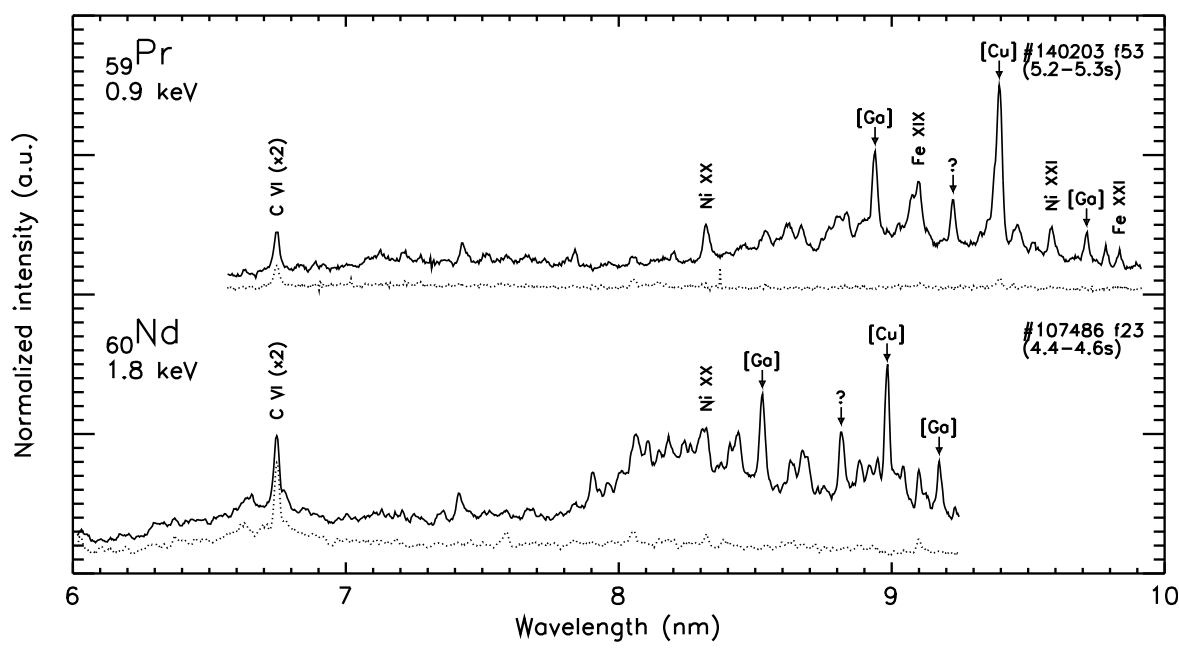

Figure 1. EUV emission spectra observed in LHD plasmas with TESPEL injections of Pr and Nd in the wavelength range of 6.0-10.0 $\mathrm{nm}$. The dotted lines indicate background spectra taken before the TESPEL injection. The spectrum of each element is normalized to its maximum intensity. Isoelectric sequence of each ion is indicated by a bracket for the identified lines.

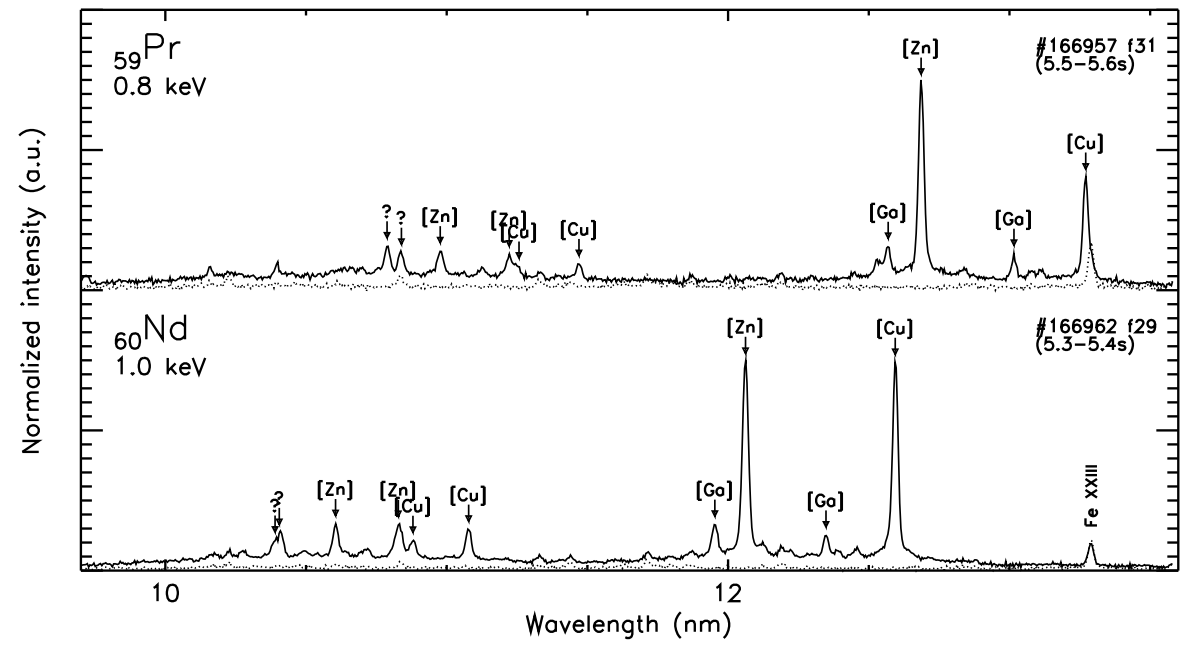

Figure 2. EUV emission spectra observed in LHD plasmas with TESPEL injections of Pr and Nd in the wavelength range of $9.7-13.6 \mathrm{~nm}$. The dotted lines indicate background spectra taken before the TESPEL injection. The spectrum of each element is normalized to its maximum intensity. Isoelectric sequence of each ion is indicated by a bracket for the identified lines. 
In our previous study for $\mathrm{Nd}$ [19], we have assigned only one line of $\mathrm{Cu}$-like $\mathrm{Nd}^{31+}$ ions and a couple of lines of Ni-like $\mathrm{Nd}^{32+}$ ions in the $6.0-9.3 \mathrm{~nm}$ wavelength range. In the present study, the other wavelength ranges have also been examined by using the two spectrometers, and the additional lines of $\mathrm{Cu}_{-}, \mathrm{Zn}-$, and Ga-like ions were identified by a comparison with the recent EBIT data [10], as indicated by vertical arrows in Figures 1 and 2. The results of the present assignments for $\mathrm{Nd}$ ions are summarized in Table 1 in which the present wavelengths $\lambda_{\text {LHD }}$ are listed together with the corresponding transitions. For comparison, the corresponding wavelengths determined at the EBIT experiment [10] and the wavelengths predicted semiempirically for $\mathrm{Cu}$ - and $\mathrm{Zn}$-like ions $[29,30]$ are also listed in Table 1. It is clearly shown in Table 1, that all of the present wavelengths are in excellent agreement with the EBIT data and the predictions.

Table 1. The assignments of the lines of neodymium ions. Isoelectric sequence of each ion is shown in a square bracket. The states of the lower and upper levels are denoted in $\mathrm{jj}$ coupling notation. The wavelengths listed in the column $\lambda_{\text {EBIT }}$ are taken from the recent EBIT data [10], and those in the column $\lambda_{\text {pred }}$ are predicted semiempirically [29,30]. All wavelengths are in $\mathrm{nm}$.

\begin{tabular}{lccccccl}
\hline & \multicolumn{2}{c}{ Lower Level } & \multicolumn{2}{c}{ Upper Level } \\
$\lambda_{\text {LHD }}$ & \multicolumn{1}{c}{ Ion } & Conf. & State & Conf. & State & $\lambda_{\text {EBIT }}[10]$ & $\lambda_{\text {pred }}[29,30]$ \\
\hline $8.984^{1}$ & $\mathrm{Nd}^{31+}[\mathrm{Cu}]$ & $4 \mathrm{p}$ & $\left(4 \mathrm{p}_{-}\right)_{1 / 2}$ & $4 \mathrm{~d}$ & $\left(4 \mathrm{~d}_{-}\right)_{3 / 2}$ & 8.9788 & 8.9825 \\
$10.880^{2}$ & $\mathrm{Nd}^{31+}[\mathrm{Cu}]$ & $4 \mathrm{~d}$ & $\left(4 \mathrm{~d}_{+}\right)_{5 / 2}$ & $4 \mathrm{f}$ & $\left(4 \mathrm{f}_{+}\right)_{7 / 2}$ & 10.8803 & 10.8836 \\
11.078 & $\mathrm{Nd}^{31+}[\mathrm{Cu}]$ & $4 \mathrm{p}$ & $\left(4 \mathrm{p}_{+}\right)_{3 / 2}$ & $4 \mathrm{~d}$ & $\left(4 \mathrm{~d}_{+}\right)_{5 / 2}$ & 11.0763 & 11.0780 \\
12.594 & $\mathrm{Nd}^{31+}[\mathrm{Cu}]$ & $4 \mathrm{~s}$ & $\left(4 \mathrm{~s}_{+}\right)_{1 / 2}$ & $4 \mathrm{p}$ & $\left(4 \mathrm{p}_{+}\right)_{3 / 2}$ & 12.5906 & 12.5911 \\
$18.912^{3}$ & $\mathrm{Nd}^{31+}[\mathrm{Cu}]$ & $4 \mathrm{~s}$ & $\left(4 \mathrm{~s}_{+}\right)_{1 / 2}$ & $4 \mathrm{p}$ & $\left(4 \mathrm{p}_{-}\right)_{1 / 2}$ & 18.9077 & 18.9095 \\
& & & & & & & \\
10.605 & $\mathrm{Nd}^{30+}[\mathrm{Zn}]$ & $4 \mathrm{~s} 4 \mathrm{~d}$ & $\left(4 \mathrm{~s}_{+}, 4 \mathrm{~d}_{+}\right)_{2}$ & $4 \mathrm{~s} 4 \mathrm{f}$ & $\left(4 \mathrm{~s}_{+}, 4 \mathrm{f}_{+}\right)_{3}$ & 10.5990 & 10.5728 \\
10.828 & $\mathrm{Nd}^{30+}[\mathrm{Zn}]$ & $4 \mathrm{~s} 4 \mathrm{p}$ & $\left(4 \mathrm{~s}_{+}, 4 \mathrm{p}_{+}\right)_{1}$ & $4 \mathrm{~s} 4 \mathrm{~d}$ & $\left(4 \mathrm{~s}_{+}, 4 \mathrm{~d}_{+}\right)_{2}$ & 10.8248 & 10.8275 \\
12.062 & $\mathrm{Nd}^{30+}[\mathrm{Zn}]$ & $4 \mathrm{~s}^{2}$ & $\left(4 \mathrm{~s}_{+}^{2}\right)_{0}$ & $4 \mathrm{~s} 4 \mathrm{p}$ & $\left(4 \mathrm{~s}_{+}, 4 \mathrm{p}_{+}\right)_{1}$ & 12.0610 & 12.0614 \\
$20.131^{3}$ & $\mathrm{Nd}^{30+}[\mathrm{Zn}]$ & $4 \mathrm{~s}^{2}$ & $\left(4 \mathrm{~s}_{+}^{2}\right)_{0}$ & $4 \mathrm{~s} 4 \mathrm{p}$ & $\left(4 \mathrm{~s}_{+}, 4 \mathrm{p}_{-}\right)_{1}$ & 20.1249 & 20.1261 \\
& & & & & & & \\
8.526 & $\mathrm{Nd}^{29+}[\mathrm{Ga}]$ & $4 \mathrm{p}$ & $\left(4 \mathrm{p}_{-}\right)_{1 / 2}$ & $4 \mathrm{~d}$ & $\left(4 \mathrm{~d}_{-}\right)_{3 / 2}$ & 8.5256 & - \\
9.175 & $\mathrm{Nd}^{29+}[\mathrm{Ga}]$ & $4 \mathrm{p}$ & $\left(4 \mathrm{p}_{-}\right)_{1 / 2}$ & $4 \mathrm{~s} 4 \mathrm{p}^{2}$ & $\left(4 \mathrm{~s}_{+},\left(4 \mathrm{p}_{+}^{2}\right)_{2}\right)_{3 / 2}$ & 9.1761 & - \\
11.953 & $\mathrm{Nd}^{29+}[\mathrm{Ga}]$ & $4 \mathrm{p}$ & $\left(4 \mathrm{p}_{-}\right)_{1 / 2}$ & $4 \mathrm{~s} 4 \mathrm{p}^{2}$ & $\left.\left(4 \mathrm{~s}_{+}, 4 \mathrm{p}_{-}\right)_{1}, 4 \mathrm{p}_{+}\right)_{1 / 2}$ & 11.9531 & - \\
12.348 & $\mathrm{Nd}^{29+}[\mathrm{Ga}]$ & $4 \mathrm{p}$ & $\left(4 \mathrm{p}_{-}\right)_{1 / 2}$ & $4 \mathrm{~s} 4 \mathrm{p}^{2}$ & $\left.\left(4 \mathrm{~s}_{+}, 4 \mathrm{p}_{-}\right)_{1}, 4 \mathrm{p}_{+}\right)_{3 / 2}$ & 12.3473 & - \\
$20.507^{3}$ & $\mathrm{Nd}^{29+}[\mathrm{Ga}]$ & $4 \mathrm{p}$ & $\left(4 \mathrm{p}_{+}\right)_{3 / 2}$ & $4 \mathrm{~s} 4 \mathrm{p}^{2}$ & $\left.\left(4 \mathrm{~s}_{+}, 4 \mathrm{p}_{-}\right)_{1}, 4 \mathrm{p}_{+}\right)_{5 / 2}$ & 20.5024 & - \\
\hline
\end{tabular}

${ }^{1}$ Already reported in [19]. ${ }^{2}$ Determined from the 3rd order spectrum. ${ }^{3}$ Observed by EUV_long spectrometer.

As mentioned above, the line of $\mathrm{Cu}$-like $\mathrm{Nd}^{31+}$ ions at $8.984 \mathrm{~nm}$ has already been reported in our previous paper [19]. A line of the Cu-like $\mathrm{Nd}^{31+}$ ions at $10.880 \mathrm{~nm}$ is partially blended with a nearby line of $\mathrm{Zn}$-like $\mathrm{Nd}^{30+}$ ions at $10.828 \mathrm{~nm}$ for the first order spectrum as shown in the bottom panel of Figure 2. However, the wavelength of this line could be determined more precisely from the corresponding third order spectrum observed in the other wavelength range in which these two adjacent lines are completely isolated because of better spectral resolution. As indicated in the footnote of Table 1, some of the lines in a longer wavelength region are observed in the EUV_long spectrometer, the wavelength resolution of which is lower than that of the SOXMOS spectrometer.

As clearly shown in Figures 1 and 2, the Pr spectrum has a structure similar to the corresponding $\mathrm{Nd}$ spectrum, and is systematically shifted to longer wavelength. Therefore, the line identifications of $\operatorname{Pr}$ ions for the transitions same as those in Table 1 have been carried out by a comparison with the corresponding spectra of $\mathrm{Nd}$ ions. The results of the identifications are listed in Table 2. To verify the present identification, we used the previous experimental data in TEXT tokamak plasmas [12-14] and the predicted wavelengths reported for $\mathrm{Cu}$ - and $\mathrm{Zn}$-like ions [29,30]. Note again that some of the wavelengths are evaluated from the second order spectra of the corresponding lines, and the EUV_long spectrometer is employed for longer wavelength region. 
Table 2. The assignments of the lines of praseodymium ions. Isoelectric sequence of each ion is shown in a square bracket. The states of the lower and upper levels are denoted in jj coupling notation. The wavelengths listed in the column $\lambda_{\text {TEXT }}$ are taken from the previous data in TEXT tokamak [12-14], and those in the column $\lambda_{\text {pred }}$ are predicted semiempirically [29,30]. All wavelengths are in $\mathrm{nm}$.

\begin{tabular}{|c|c|c|c|c|c|c|c|}
\hline \multirow[b]{2}{*}{$\lambda_{\text {LHD }}$} & \multirow[b]{2}{*}{ Ion } & \multicolumn{2}{|c|}{ Lower Level } & \multicolumn{2}{|r|}{ Upper Level } & \multirow[b]{2}{*}{$\lambda_{\text {TEXT }}[12-14]$} & \multirow[b]{2}{*}{$\lambda_{\text {pred }}[29,30]$} \\
\hline & & Conf. & State & Conf. & State & & \\
\hline $9.394^{1}$ & $\operatorname{Pr}^{30+}[\mathrm{Cu}]$ & $4 p$ & $\left(4 p_{-}\right)_{1 / 2}$ & $4 \mathrm{~d}$ & $\left(4 d_{-}\right)_{3 / 2}$ & - & 9.3980 \\
\hline $11.257^{2}$ & $\operatorname{Pr}^{30+}[\mathrm{Cu}]$ & $4 d$ & $\left(4 d_{+}\right)_{5 / 2}$ & $4 \mathrm{f}$ & $\left(4 \mathrm{f}_{+}\right)_{7 / 2}$ & 11.23 & 11.2457 \\
\hline 11.470 & $\operatorname{Pr}^{30+}[\mathrm{Cu}]$ & $4 p$ & $\left(4 \mathrm{p}_{+}\right)_{3 / 2}$ & $4 d$ & $\left(4 d_{+}\right)_{5 / 2}$ & 11.47 & 11.4709 \\
\hline $13.271^{3}$ & $\operatorname{Pr}^{30+}[\mathrm{Cu}]$ & $4 \mathrm{~s}$ & $\left(4 s_{+}\right)_{1 / 2}$ & $4 p$ & $\left(4 p_{+}\right)_{3 / 2}$ & 13.233 & 13.2699 \\
\hline $19.546^{4}$ & $\operatorname{Pr}^{30+}[\mathrm{Cu}]$ & $4 \mathrm{~s}$ & $\left(4 s_{+}\right)_{1 / 2}$ & $4 \mathrm{p}$ & $\left(4 p_{-}\right)_{1 / 2}$ & 19.58 & 19.5466 \\
\hline 10.977 & $\operatorname{Pr}^{29+}[\mathrm{Zn}]$ & $4 \mathrm{~s} 4 \mathrm{~d}$ & $\left(4 \mathrm{~s}_{+}, 4 \mathrm{~d}_{+}\right)_{2}$ & $4 \mathrm{~s} 4 \mathrm{f}$ & $\left(4 \mathrm{~s}_{+}, 4 \mathrm{f}_{+}\right)_{3}$ & - & 10.9480 \\
\hline $11.225^{2}$ & $\operatorname{Pr}^{29+}[\mathrm{Zn}]$ & $4 s 4 p$ & $\left(4 \mathrm{~s}_{+}, 4 \mathrm{p}_{+}\right)_{1}$ & $4 \mathrm{~s} 4 \mathrm{~d}$ & $\left(4 \mathrm{~s}_{+}, 4 \mathrm{~d}_{+}\right)_{2}$ & 11.10 & 11.2233 \\
\hline 12.686 & $\operatorname{Pr}^{29+}[\mathrm{Zn}]$ & $4 s^{\frac{1}{2}}$ & $\left(4 s_{+}^{2}\right)_{0}$ & $4 s 4 p$ & $\left(4 s_{+}, 4 p_{+}\right)_{1}$ & 12.68 & 12.6833 \\
\hline $20.846^{4}$ & $\operatorname{Pr}^{29+}[\mathrm{Zn}]$ & $4 s^{2}$ & $\left(4 s_{+}^{2}\right)_{0}$ & $4 s 4 p$ & $\left(4 \mathrm{~s}_{+}, 4 \mathrm{p}_{-}\right)_{1}$ & 20.83 & 20.8406 \\
\hline 8.939 & $\operatorname{Pr}^{28+}[\mathrm{Ga}]$ & $4 p$ & $\left(4 p_{-}\right)_{1 / 2}$ & $4 d$ & $\left(4 d_{-}\right)_{3 / 2}$ & 8.77 & - \\
\hline 9.714 & $\operatorname{Pr}^{28+}[\mathrm{Ga}]$ & $4 \mathrm{p}$ & $\left(4 \mathrm{p}_{-}\right)_{1 / 2}$ & $4 s 4 p^{2}$ & $\left(4 \mathrm{~s}_{+},\left(4 \mathrm{p}_{+}^{2}\right)_{2}\right)_{3 / 2}$ & - & - \\
\hline 12.569 & $\operatorname{Pr}^{28+}[\mathrm{Ga}]$ & $4 p$ & $\left(4 \mathrm{p}_{-}\right)_{1 / 2}$ & $4 s 4 p^{2}$ & $\left.\left(4 \mathrm{~s}_{+}, 4 \mathrm{p}_{-}\right)_{1}, 4 \mathrm{p}_{+}\right)_{1 / 2}$ & 12.57 & - \\
\hline 13.016 & $\operatorname{Pr}^{28+}[\mathrm{Ga}]$ & $4 p$ & $\left(4 \mathrm{p}_{-}\right)_{1 / 2}$ & $4 s 4 p^{2}$ & $\left.\left(4 \mathrm{~s}_{+}, 4 \mathrm{p}_{-}\right)_{1}, 4 \mathrm{p}_{+}\right)_{3 / 2}$ & $12.980,12.83$ & - \\
\hline 21.245 & $\operatorname{Pr}^{28+}[\mathrm{Ga}]$ & $4 \mathrm{p}$ & $\left(4 \mathrm{p}_{+}\right)_{3 / 2}$ & $4 s 4 p^{2}$ & $\left.\left(4 \mathrm{~s}_{+}, 4 \mathrm{p}_{-}\right)_{1}, 4 \mathrm{p}_{+}\right)_{5 / 2}$ & - & - \\
\hline
\end{tabular}

${ }^{1}$ Blended with Fe XVIII. ${ }^{2}$ Determined from the 2nd order spectrum. ${ }^{3}$ Partially blended with Fe XXIII. ${ }^{4}$ Observed by EUV_long spectrometer.

For Ga-like ions, $Z$ dependence of the specified transition wavelength has also been examined for an unambiguous identification because no predicted wavelengths have been reported previously. Since the EBIT data for the lanthanide elements with even atomic numbers from 60-70 are available [6-10], $Z$ dependence for a specific transition can be plotted to verify the identifications. For example, the wavelength of the transition $4 s^{2} 4 p$ $\left[\left(4 \mathrm{p}_{+}\right)_{3 / 2}\right]-4 \mathrm{~s} 4 \mathrm{p}^{2}\left[\left(\left(4 \mathrm{~s}_{+}, 4 \mathrm{p}_{-}\right)_{1}, 4 \mathrm{p}_{+}\right)_{5 / 2}\right]$ is plotted as a function of $\mathrm{Z}$ in Figure 3 . The EBIT data for $Z=60,62,66,68$ and 70 are plotted with diamonds, and a second order polynomial fitting curve to the EBIT data is drawn by a solid line in Figure 3, where the second order polynomial was chosen to avoid overfitting. The present results of the LHD (triangles) for $Z=59$ and 60 are very close to the extrapolation of the fitted curve, which implies that the present assignment would be reasonable. The analyses of $Z$ dependence of the transition wavelengths are still ongoing for the other transitions by comparisons with theoretical calculations, which will be reported in a separate paper.

Unfortunately, a line of Cu-like $\operatorname{Pr}^{30+}$ ions for the $4 \mathrm{p}-4 \mathrm{~d}$ transition at $9.394 \mathrm{~nm}$ is completely blended with an intense line of F-like $\mathrm{Fe}^{17+}$ ions. Though another line of $\mathrm{Cu}$-like $\operatorname{Pr}^{30+}$ ions at $13.271 \mathrm{~nm}$ is partially blended with the resonance line of Be-like $\mathrm{Fe}^{22+}$ ions at $13.291 \mathrm{~nm}$, it is distinguishable because the peak position for $\mathrm{Pr}^{30+}$ is clearly deviated to shorter wavelength side of the position for $\mathrm{Fe}^{22+}$, as shown in the top panel of Figure 2. It is notable that one line for $\mathrm{Zn}$-like $\mathrm{Pr}^{29+}$ ions and two lines of Ga-like $\mathrm{Pr}^{28+}$ ions have been identified experimentally for the first time in the present study. For Pr ions, some of the wavelengths measured previously in tokamak plasmas are largely deviated from the present results. This is probably due to low wavelength resolution and line blending with the quasi-continuum feature in the previous studies.

There still remain a few unidentified lines of Pr and $\mathrm{Nd}$ ions, as indicated by question marks in Figures 1 and 2. These lines certainly originate from the injected elements because they only appear after the TESPEL injections. Even though these lines for Nd ions are not listed in the recent EBIT data [10], they probably originate from lower ion stages such as Ge-like ions because they become relatively more intense as the electron temperature decreases. As the spectral structure including Ge-like ions is more complicated due to the 
larger number of lines involved, further investigations using atomic structure calculations and collisional-radiative models should be required for the assignments of these lines.

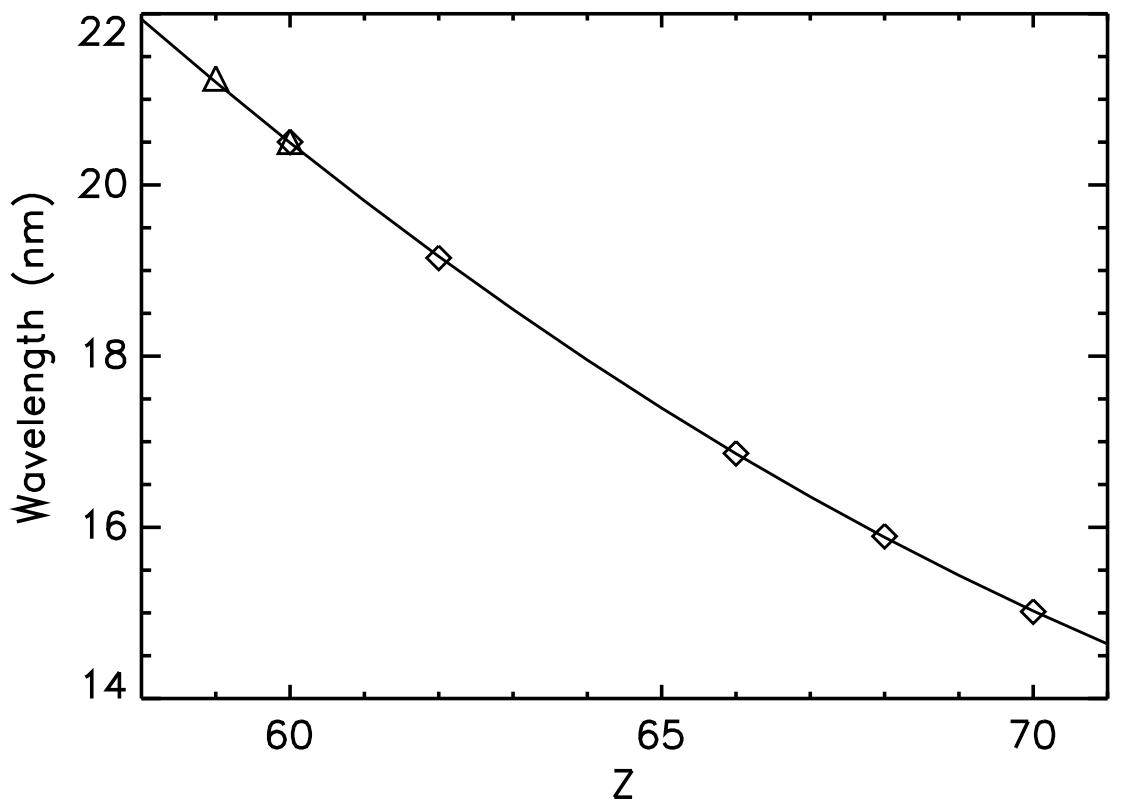

Figure 3. $Z$ dependence of the wavelength for the transition $4 s^{2} 4 p\left[\left(4 p_{+}\right)_{3 / 2}\right]-4 s 4 p^{2}$ $\left[\left(\left(4 \mathrm{~s}_{+}, 4 \mathrm{p}_{-}\right)_{1}, 4 \mathrm{p}_{+}\right)_{5 / 2}\right]$ of Ga-like ions. The line is a second order polynomial fitting of the EBIT data [6-10]. The wavelengths recorded in the NIST EBIT are plotted with diamonds, while those in LHD are plotted with triangles for $Z=59$ and 60 .

\section{Summary}

We have analyzed discrete spectra of highly charged Pr and Nd ions in optically thin high-temperature LHD plasmas in the wavelength range of 6-22 $\mathrm{nm}$. We have successfully made assignments of the lines corresponding to 14 transitions of $\mathrm{Ga}$-like to $\mathrm{Cu}$-like ions for each element. The line identifications for $\mathrm{Nd}$ ions were easily performed by a comparison with the data recorded in the NIST EBIT, while the lines of Pr ions were identified from the similarity of the spectral features of both elements. We determined the wavelengths for the lines of Pr ions more accurately in comparison with the previous studies, and some of them have been identified experimentally for the first time in the LHD. The spectral data analyses for the other lanthanide elements are still ongoing to find new lines and clarify $Z$ dependence of the transition wavelengths, the results of which will be reported in future publications.

Author Contributions: Conceptualization, C.S., F.K. and I.M.; methodology, C.S. and F.K.; validation, C.S., F.K. and I.M.; formal analysis, C.S.; investigation, C.S., T.O. and N.T.; resources, C.S., T.O. and N.T.; data curation, C.S. and T.O.; writing-original draft preparation, C.S.; writing-review and editing, F.K. and I.M.; visualization, C.S.; supervision, F.K. and I.M.; project administration, I.M.; funding acquisition, C.S., F.K. and I.M. All authors have read and agreed to the published version of the manuscript.

Funding: This research was funded by JSPS KAKENHI grant numbers 15H03759, $19 \mathrm{H} 01881$ and 21K03515.

Institutional Review Board Statement: Not applicable.

Informed Consent Statement: Not applicable.

Data Availability Statement: Not applicable. 
Acknowledgments: The authors acknowledge the LHD experimental group for their assistance. This work was also partially funded by the NIFS-collaboration research program (NIFS20KLPF078, NIFS21KLPF083).

Conflicts of Interest: The authors declare no conflict of interest.

\section{References}

1. O'Sullivan, G.; Carroll, P.K. 4d-4f emission resonances in laser-produced plasmas. J. Opt. Soc. Am. 1981, 71, 227-230. [CrossRef]

2. Mandelbaum, P.; Finkenthal, M.; Schwob, J.L.; Klapisch, M. Interpretation of the quasicontinuum band emitted by highly ionized rare-earth elements in the 70-100-Å range. Phys. Rev. A 1987, 35, 5051-5059. [CrossRef] [PubMed]

3. Finkenthal, M.; Lippmann, S.; Huang, L.K.; Moos, H.W.; Lee, Y.T.; Spector, N.; Zigler, A.; Yarkoni, E. $\Delta n=0 N$-shell emission of rare-earth ions $(Z=59$ to 70$)$ emitted from low and high density tokamak and laser produced plasmas. Phys. Scr. 1990, 41, 445-448. [CrossRef]

4. Suzuki, C.; Koike, F.; Murakami, I.; Tamura, N.; Sudo, S.; Sakaue, H.A.; Nakamura, N.; Morita, S.; Goto, M.; Kato, D.; et al. EUV spectroscopy of highly charged high Z ions in the Large Helical Device plasmas. Phys. Scr. 2014, 89, 114009. [CrossRef]

5. Suzuki, C.; Murakami, I.; Koike, F.; Tamura, N.; Sakaue, H.A.; Morita, S.; Goto, M.; Kato, D.; Ohashi, H.; Higashiguchi, T.; et al. Extreme ultraviolet spectroscopy and atomic models of highly charged heavy ions in the Large Helical Device. Plasma Phys. Control. Fusion 2017, 59, 014009. [CrossRef]

6. Kilbane, D.; O'Sullivan, G.; Gillaspy, J.D.; Ralchenko, Y.; Reader, J. EUV spectra of Rb-like to Cu-like gadolinium ions in an electron-beam ion trap. Phys. Rev. A 2012, 86, 042503. [CrossRef]

7. Kilbane, D.; O'Sullivan, G.; Podpaly, Y.A.; Gillaspy, J.D.; Reader, J.; Ralchenko, Y. EUV spectra of Rb-like to Ni-like dysprosium ions in an electron beam ion trap. Eur. Phys. J. D 2014, 68, 222. [CrossRef]

8. Podpaly, Y.A.; Gillaspy, J.D.; Reader, J.; Ralchenko, Y. Measurements and identifications of extreme ultraviolet spectra of highlycharged Sm and Er. J. Phys. B At. Mol. Opt. Phys. 2015, 48, 025002. [CrossRef]

9. Dipti, F.N.; Silwal, R.; Dreiling, J.M.; Sanders, S.C.; Takacs, E.; Ralchenko, Y. Spectroscopic analysis of N-intrashell transitions in Rb-like to Ni-like Yb ions. J. Phys. B At. Mol. Opt. Phys. 2020, 53, 145002.

10. Suzuki, C.; Dipti, F.; Yang, Y.; Gall, A.; Silwal, R.; Sanders, S.; Naing, A.; Tan, J.; Takacs, E.; Ralchenko, Y. Identifications of extreme ultraviolet spectra of Br-like to Ni-like neodymium ions using an electron beam ion trap. J. Phys. B At. Mol. Opt. Phys. 2021, 54, 015001. [CrossRef]

11. Acquista, N.; Reader, J. $4 \mathrm{~s}^{2}{ }^{1} \mathrm{~S}_{0}-4 \mathrm{~s} 4 \mathrm{p}{ }^{1} \mathrm{P}_{1}$ transitions in zinclike ions. J. Opt. Soc. Am. B 1984, 1, 649-651. [CrossRef]

12. Finkenthal, M.; Lippmann, A.S.; Huang, L.K.; Yu, T.L.; Stratton, B.C.; Moos, H.W.; Klapisch, M.; Mandelbaum, P.; Bar Shalom, A.; Hodge, W.L.; et al. The spectrum of highly ionized praseodymium and dysprosium from the Texas tokamak plasma in the 50-250- ̊ range. J. Appl. Phys. 1986, 59, 3644-3649. [CrossRef]

13. Mandelbaum, P.; Finkenthal, M.; Meroz, E.; Schwob, J.L.; Oreg, J.; Goldstein, W.H.; Osterheld, L.; Bar-Shalom, A.; Lippmann, S.; Huang, L.K.; et al. Effect of excitation-autoionization processes on the line emission of Zn I- and Ga I-like rare-earth ions in hot coronal plasmas. Phys. Rev. A 1990, 42, 4412-4415. [CrossRef]

14. Fournier, K.B.; Goldstein, W.H.; Osterheld, A.; Finkenthal, M.; Lippmann, S.; Huang, L.K.; Moos, H.W.; Spector, N. Soft x-ray emission of galliumlike rare-earth atoms produced by high-temperature low-density tokamak and high-density laser plasmas. Phys. Rev. A 1994, 50, 2248-2256. [CrossRef]

15. Reader, J.; Luther, G. The copper isoelectronic sequence: $\mathrm{Ba}^{27+}-\mathrm{W}^{45+}$. Phys. Scr. 1981, 24, 732-737. [CrossRef]

16. Hinnov, E.; Beiersdorfer, P.; Bell, R.; Stevens, J.; Suckewer, S.; von Goeler, S.; Wouters, A.; Dietrich, D.; Gerassimenko, M.; Silver, E. Intercombination lines of the zinc isoelectronic sequence for $\mathrm{Z}=50-70$. Phys. Rev. A 1987, 35, 4876-4877. [CrossRef]

17. Seely, J.F.; Feldman, U.; Wouters, A.W.; Schwob, J.L.; Suckewer, S. Discrepancies between calculated and observed energies for 4s-4p transitions in highly charged Cu-like ions. Phys. Rev. A 1989, 40, 5020-5025. [CrossRef]

18. Sugar, J.; Kaufman, V.; Baik, D.H.; Kim, Y.-K.; Rowan, W.L. Accurate wavelengths for resonance lines of the Cu I and Zn I isoelectronic sequences for Pd to Dy. J. Opt. Soc. Am. B 1991, 8, 1795-1798. [CrossRef]

19. Suzuki, C.; Koike, F.; Murakami, I.; Tamura, N.; Sudo, S. Observation of EUV spectra from gadolinium and neodymium ions in the Large Helical Device. J. Phys. B At. Mol. Opt. Phys. 2012, 45, 135002. [CrossRef]

20. Suzuki, C.; Koike, F.; Murakami, I.; Tamura, N.; Sudo, S. Temperature dependent EUV spectra of Gd, Tb and Dy ions observed in the Large Helical Device. J. Phys. B At. Mol. Opt. Phys. 2015, 48, 144012. [CrossRef]

21. Suzuki, C.; Koike, F.; Murakami, I.; Tamura, N.; Sudo, S. Systematic observation of EUV spectra from highly charged lanthanide ions in the Large Helical Device. Atoms 2018, 6, 24. [CrossRef]

22. Suzuki, C.; Koike, F.; Murakami, I.; Tamura, N.; Sudo, S.; O'Sullivan, G. Soft x-ray spectroscopy of rare-earth elements in LHD plasmas. Atoms 2019, 7, 66. [CrossRef]

23. Takeiri, Y.; Morisaki, T.; Osakabe, M.; Yokoyama, M.; Sakakibara, S.; Takahashi, H.; Nakamura, Y.; Oishi, T.; Motojima, G.; Murakami, S.; et al. Extension of the operational regime of the LHD towards a deuterium experiment. Nucl. Fusion 2017, $57,102023$. [CrossRef]

24. Takeiri, Y. Advanced Helical Plasma Research towards a Steady-State Fusion Reactor by Deuterium Experiments in Large Helical Device. Atoms 2018, 6, 69. [CrossRef] 
25. Sudo, S.; Tamura, N.; Khlopenkov, K.; Muto, S.; Funaba, H.; Viniar, I.; Sergeev, V.; Sato, K.; Ida, K.; Kawahata, K.; et al. Particle transport diagnostics on CHS and LHD with tracer-encapsulated solid pellet injection. Plasma Phys. Control. Fusion 2002, 44, 129-135. [CrossRef]

26. Sudo, S.; Tamura, N. Tracer-encapsulated solid pellet injection system. Rev. Sci. Instrum. 2012, 83, 023503. [CrossRef]

27. Schwob, J.L.; Wouters, A.W.; Suckewer, S.; Finkenthal, M. High-resolution duo-multichannel soft-x-ray spectrometer for tokamak plasma diagnostics. Rev. Sci. Instrum. 1987, 58, 1601-1615. [CrossRef]

28. Chowdhuri, M.B.; Morita, S.; Goto, M.; Nishimura, H.; Nagai, K.; Fujioka, S. Spectroscopic comparison between 1200 grooves/mm ruled and holographic gratings of a flat-field spectrometer and its absolute sensitivity calibration using bremsstrahlung continuum. Rev. Sci. Instrum. 2007, 78, 023501. [CrossRef]

29. Brown, C.M.; Seely, J.F.; Kania, D.R.; Hammel, B.A.; Back, C.A.; Lee, R.W.; Bar-Shalom, A.; Behring, W.E. Wavelengths and Energy Levels for the Zn I Isoelectronic Sequence $\mathrm{Sn}^{20+}$ through $\mathrm{U}^{62+}$. At. Data Nucl. Data Tables 1994, 58, 203-217. [CrossRef]

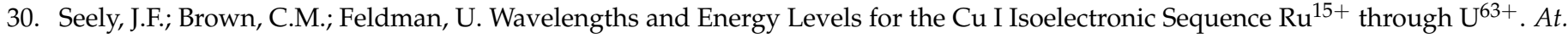
Data Nucl. Data Tables 1989, 43, 145-159. [CrossRef] 